\title{
In silico identification of common epitopes from pathogenic mycobacteria
}

\author{
Bárbara de la Caridad Addine Ramírez ${ }^{1}$, Reynel Marrón ${ }^{1}$, Rommel Calero ${ }^{1}$, Mayelin Mirabal ${ }^{1}$, Juan Carlos Ramírez ${ }^{1}$, \\ María E Sarmiento ${ }^{1}$, Mohd Nor Norazmi ${ }^{2,3}$, Armando Acosta ${ }^{1 *}$
}

From Second International Congress on Immunopharmacology 2011

Varadero Beach, Cuba. 26-30 June 2011

\begin{abstract}
An in silico study was carried out to identify antigens for their possible collective use as vaccine candidates against diseases caused by different classes of pathogenic mycobacteria with significant clinical relevance. The genome sequences of the relevant causative agents were used in order to search for orthologous genes among them. Bioinformatics tools permitted us to identify several conserved sequences with $100 \%$ identity with no possibility of cross-reactivity to the normal flora and human proteins. Nine different proteins were characterized using the strain H37Rv as reference and taking into account their functional category, their in vivo expression and subcellular location. T and B cell epitopes were identified in the selected sequences. Theoretical prediction of population coverage was calculated for individual epitopes as well as their combinations. Several identical sequences, belonging to six proteins containing $T$ and $B$ cell epitopes which are not present in selected microorganisms of the normal microbial flora or in human proteins were obtained.
\end{abstract}

\section{Introduction}

There are different species of mycobacteria that cause many human infections with high mortality and morbility $[1,2]$. Three of the most common diseases caused by them are tuberculosis (TB), leprosy and Buruli ulcer.

Atypical mycobacteria are the causative agents of diseases caused by mycobacteria other than M. tuberculosis (MTB) and M. leprae. Infections with these species have become more frequent nowadays. HIV infection, socioeconomic conditions and antibiotic resistance are some of the reasons for the increased prevalence of these diseases [3]. This fact may also be associated with the waning protective effect of BCG [4].

The absence of an effective vaccine against mycobacterial diseases [5-7] and its high prevalence in poor countries with low accessibility to health services justified the search for vaccine candidates that can be used to simultaneously protect humans against diseases caused by the different pathogenic mycobacteria [8].

\footnotetext{
* Correspondence: aracosta2005@yahoo.es

${ }^{1}$ Finlay Institute. Ave. 27, No. 19805, La Lisa. La Habana, Cuba

Full list of author information is available at the end of the article
}

Vaccine design can be expedited via the application of in silico techniques combined with immunological methods. Bioinformatics tools enable researchers to move rapidly from genomic sequence to vaccine design. These new tools allow the selection of regions of microbial genomes that are predicted to trigger protective immune responses to be used as components for vaccine constucts $[9,10]$.

The present research aims to identify antigens using in silico studies for the development of vaccine candidates that can simultaneously protect humans against diseases caused by pathogenic mycobacteria.

\section{Materials and methods}

The mycobacteria genomes were retrieved from Gene Bank database (http://www.ncbi.nlm.nih.gov/).

A whole-genome alignment was performed using Mauve tools in order to search for orthologous genes with identities ranging from 98 to $100 \%$ homology.

A local alignment among all protein sequences for each orthologous genes was perfomed with Clustalw program, and all sequences having identity of more than 20 continuous amino acids were chosen.

\section{()

(c) 2013 de la Caridad Addine Ramírez et al; licensee BioMed Central Ltd. This is an Open Access article distributed under the terms of the Creative Commons Attribution License (http://creativecommons.org/licenses/by/2.0), which permits unrestricted use, distribution, and reproduction in any medium, provided the original work is properly cited. 
Selection of similar genetic regions among mycobacteria and genetic regions from selected bacterial flora of the normal microbiome was also performed.

The amino acid sequences obtained were compared with the available sequences of selected microbiome using the local alignment tool FASTA 36.3.4. The parameters for the program were $k t u p=2$, DNA $S T R A N D=N / A$ and SEQUENCE $=$ PROTEIN.

Nine agents were selected for the comparison:

Bacteroides fragilis $638 R$

Bifidobacterium bifidum PRL2010

Clostridium dificile

Escherichia coli 'BL21-Gold (DE3)pLysS AG'

Lactobacillus acidophilus NCFM

Mycobacterium smegmatis str. MC2 155

Staphylococcus epidermidis ATCC 12228,

Streptococcus agalactiae $2603 \mathrm{~V} / \mathrm{R}$

Streptococcus sanguinis SK36.

Finally, sequences below 70\% homology and those without theoretical possibilities of forming linear B cell epitopes were selected.

\section{Prediction of subcellular localization of proteins}

The subcelular localization of the selected proteins was defined using the report of the identification and localization of 1044 MTB proteins [11].

Subcelular localization of proteins that did not appear in the report was predicted using three servers: PSORTb [12], TBpred, [13] and SignalP [14].

\section{Identification and selection of in-vivo expressed genes}

A bibliographic search was performed to look for reports of in-vivo studies of MTB gene expression in humans and animals using google scholar, PubMed and PubMed Central.

\section{HLAPred server was used for prediction of T-cell epitopes} in this study

Thirty six HLA class I and 51 HLA class II were selected for the prediction. The results were displayed in HTML Mapping form and the threshold of $3 \%$ were use as default for the prediction parameters [11]. T cell epitopes similar to human epitopes were eliminated.

\section{B-cell epitope prediction}

Two servers, Bcepred and ABCpred, were combined for the prediction of linear B cell epitomes. For Bcepred server: Seven physico-chemical properties of amino acids (hydrophilicity, flexibility, accessibility, polarity, exposed surface and turns and antigenic propensity) were combined with a threshold at 2.38. For ABCpred server: A threshold of 0.5 and the predicted B cell epitope length of 16 amino acids were used [12]. The regions containing both $\mathrm{T}$ and $\mathrm{B}$ cell epitopes were selected by BioHelper tools [15].

The epitopes analyzed were compared with the report of Iñakis et al. [16] for eliminating hyperconserved epitopes.

\section{Population coverage calculation of individual epitopes and their combinations}

The theoretical prediction of the presentation of the individual epitopes and their combinations for MHC alleles of Cuban, Malaysian, Brazilian, Mexican, Australian, African, and North American populations were calculated using the Population Coverage Calculation program [18].

The percentage of coverage greater than $70 \%$ was accepted as good consistent with reports in the literature $[18,10,19,11,14]$ (figure 1 ).

\section{Results}

Thirteen-whole mycobacteria genome alignments were performed and 26 orthologous genes were determined. A local alignment among each protein sequence for each orthologous gene was performed and 71 sequences were obtained with more than 20 identical amino acids between them, corresponding to 14 proteins.

In order to avoid the selection of epitopes share with the host microbiome only, only 20 epitopes were retained in this study. It was found that 13 of 14 proteins were expressed in the membrane; with six only expressed in the membrane, two in the membrane and cell wall; three in the membrane and cytosol and two in all of these compartments. One protein was only expressed in the cytosol $[20,21]$.

Table 1 shows a characterization of predicted proteins containing sequences showing 100\% identity among pathogenic mycobacteria, and not shared with human proteins or the normal human microbiome. These proteins have also been predicted to contain $\mathrm{T}$ and/ or $\mathrm{B}$ cell epitopes, and are expressed during infection.

Four of the identified genes (Rv1269, Rv0667, Rv1547 and Rv1384) have been reported to be up-regulated during infection. Rv1299 is over-expressed during infection in human macrophages, mice and guinea pig lungs [22]. Rv0667, Rv1547and Rv1384 are over-expressed only during infection in guinea pig lungs [23].

The selected sequences from Rv0701, Rv1384 and Rv1308 are not predicted to contain $\mathrm{T}$ cell epitopes but were chosen based on reports of their potential role in the humoral immune response against MTB [23-25].

Hyperconserved epitopes are not present in the selected sequences. These sequences were excluded to avoid regions, which may be selected during the co-evolution of MTB and humans and hence may provide an advantage to the pathogen [17]. 


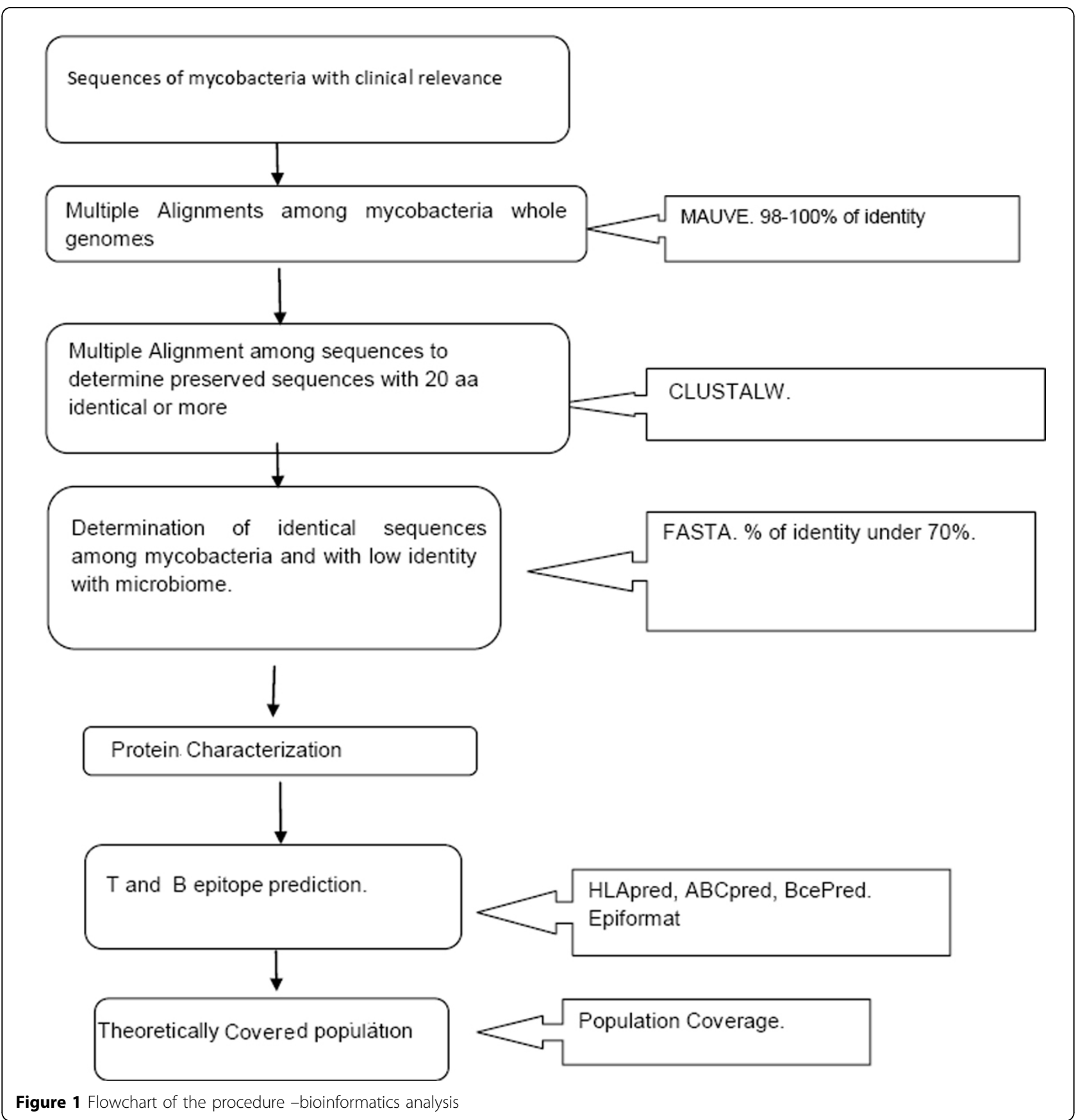

Five sequences that contain epitopes similar to human epitopes were eliminated [13] to avoid potential autoimmune response.

In this research, the identified sequences belonging to 15 MTB proteins and some of its combinations were analyzed. The combination of all sequences were predicted to give more than $70 \%$ population coverage when presented via the MHC class I plus MHC class II molecules in the selected geographical regions. In contrast, the predicted population coverage of individual sequences was highly variable in the different geographical regions and was always bellow $70 \%$ (data not shown). However, these sequences were not excluded because of their potential use in the specific geographical regions.

The combination of all sequences shows population coverage over $70 \%$ in all geographical regions studied (Figure 2).

Evaluation of the identified sequences in in vitro and in animal models should be carried out to verify their utility to be included in vaccine formulations. 
Table 1 Characterization of predicted proteins

\begin{tabular}{llll}
\hline Identification (ORF) & T epitopes & B epitopes & Up-regulation during infection \\
\hline Rv0667 & YES & YES & YES \\
\hline Rv1299 & YES & NO & YES \\
\hline Rv1315 & YES & YES & NO \\
\hline Rv1420 & YES & NO & NO \\
\hline Rv1421 & YES & YES & NO \\
\hline Rv1547 & YES & YES & YES \\
\hline Rv0701 & NO & YES & NO \\
\hline Rv1308 & NO & YES & NO \\
\hline Rv1384 & NO & YES & YES \\
\hline
\end{tabular}

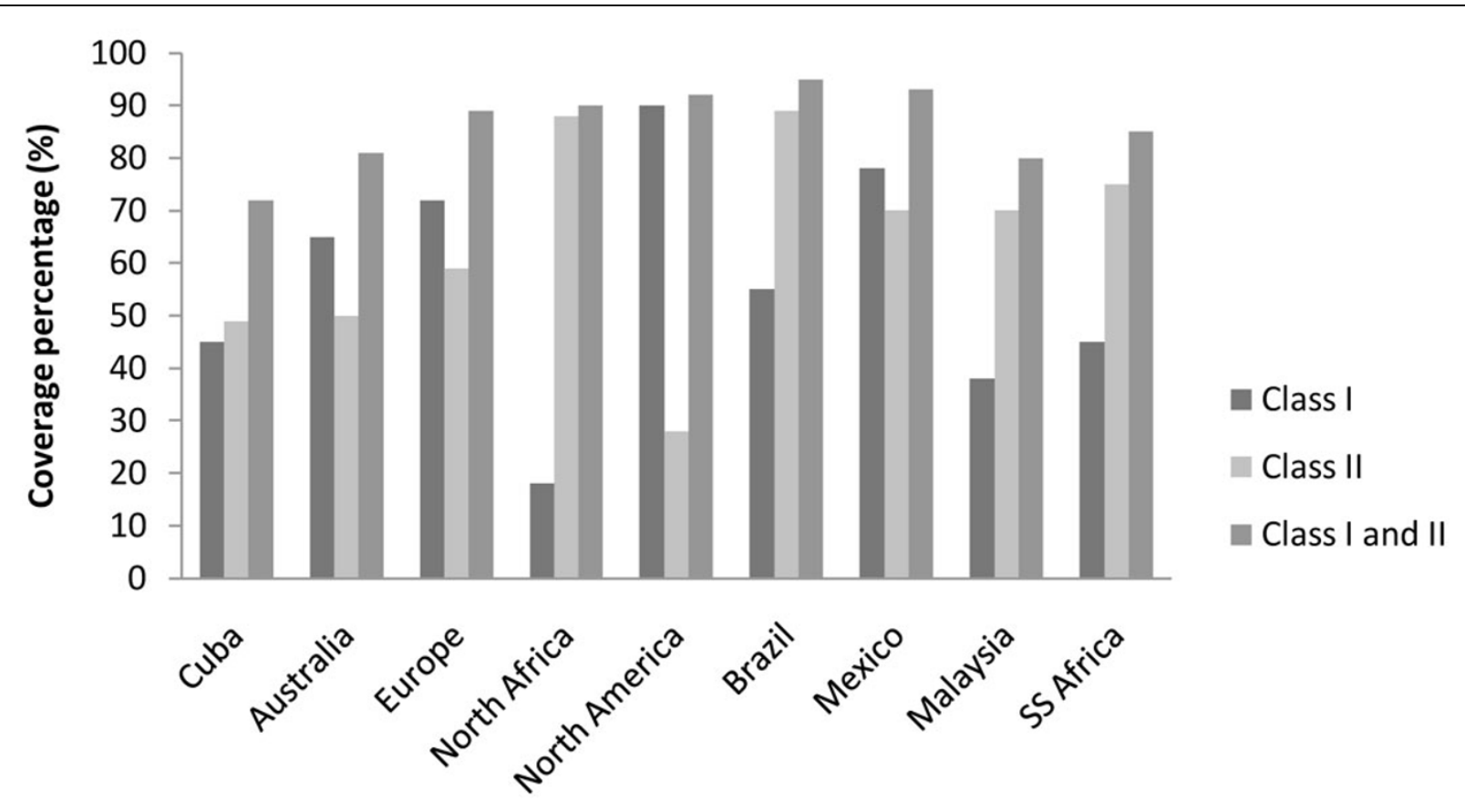

populations

Figure 2 Population coverage for combination of all sequences

\section{Conclusions}

We used bioinformatics tools to predict sequences, which are common among different mycobacteria belonging to the MTB complex and are absent from selected microorganisms of the normal flora. The predicted sequences comprise those that are expressed primarily in the membrane and contain $B$ and $T$ cell epitopes that do not match with the human epitopic database. The combination of the identified sequences gives appropriated theoretical population coverage in the different geographic regions studied. These predicted sequences are potential vaccine candidates but functional/biological assays should be performed to verify whether they are indeed appropriate to be included in a vaccine formulation.

\section{Authors' contributions}

All authors have read and approved the final manuscript BCAR, performed the bioinformatics studies and participated in data analysis and in writing of the manuscript. RC developed softwares used in the bioinformatics studies, performed the bioinformatics studies and participated in data analysis and in writing of the manuscript. RM,MM, JCR helped in the bioinformatics studies. MES, MNN, AA conceived the study, participated in data analysis and in writing of the manuscript.

\section{Competing interests}

The authors declare that they have no competing financial interests. 


\section{Acknowledgements}

This work was supported by the Ministry of Science, Technology and Innovation, Malaysia (10-01-05-MEB002) and the Ministry of Higher Education, Malaysia LRGS Grant (203.PSK.6722001) and Ministry of Science and Technology, Cuba

\section{Declarations}

This article has been published as part of BMC Immunology Volume 14 Supplement 1, 2013: Proceedings from Delivery Systems and Current strategies to drug design. The full contents of the supplement are available online at http://www.biomedcentral.com/bmcimmunol/supplements/14/S1

\section{Author details}

'Finlay Institute. Ave. 27, No. 19805, La Lisa. La Habana, Cuba. ${ }^{2}$ School of Health Sciences Universiti Sains Malaysia, Malaysia. ${ }^{3}$ Institute for Research in Molecular Medicine, Universiti Sains Malaysia, Malaysia.

Published: 25 February 2013

\section{References}

1. Smith I: Mycobacterium tuberculosis Pathogenesis and Molecular Determinants of Virulence. Clin. Microbiol. Rev 2003, 16(3):463-496.

2. Martín C, Bigi F, Gicquel B: New Vaccines against Tuberculosis. Tuberculosis 2007: From basic science to patient care, First 2007, 341-360.

3. Vargas García R: Epidemiología de las micobacteriosis atípicas en la salud humana. BNF Emerge 2008, 2(4):220-230.

4. Marcel AB: Mycobacterium du jour: what's on tomorrow's menu? Microbes and Infection 2008, 10(9):968-972.

5. Young DB, Perkins MD, Duncan K, Barry CE 3rd: Confronting the scientific obstacles to global control of tuberculosis. J Clin Invest 2008, 118(4):1255-65.

6. Dye C: Tuberculosis 2000-2010: control, but not elimination. Int J Tuberc Lung Dis 2000, 4(12 Suppl 2):S146-52.

7. Norazmi MN, Sarmiento ME, Acosta A: Recent advances in tuberculosis vaccine development. Current Respiratory Medicine Reviews 2005, 1(2):109-116.

8. Ochoa Azze RF: Inmunoepidemiología y estrategia de vacunación. Ediciones Finlay Ciudad de la Habana; 2008.

9. Pearson WR, Lipman DJ: Improved tools for biological sequence comparison. Proceedings of the National Academy of Sciences of the United States of America 1988, 85(8):2444-8.

10. Li Pira G, Ivaldi F, Moretti P, Manca F: High throughput T epitope mapping and vaccine development. J Biomed Biotechnol 2010, Epub 2010: 325720 .

11. Saha S, Raghava GPS: Prediction of Continuous B-cell Epitopes in an Antigen Using Recurrent Neural Network. Proteins 2006, 65(1):40-48.

12. Mawuenyega KG, Forst CV, Dobos KM, Belisle JT, Chen J, Bradbury EM, et al: Mycobacterium tuberculosis functional network analysis by global subcellular protein profiling. Molecular Biology of the Cell 2004, 16:396-404.

13. Yu NY, Wagner JR, Laird MR, Melli G, Rey S, Lo R, et al: PSORTb 3.0: improved protein subcellular localization prediction with refined localization subcategories and predictive capabilities for all prokaryotes. Bioinformatics 2010, 26(13):1608-15.

14. Rashid M, Saha S, Raghava GPS: Support Vector Machine-based method for predicting subcellular localization of mycobacterial proteins using evolutionary information and motifs. BMC Bioinformantics 2007, 8:337.

15. Romel Calero Ramos: Análisis in silico de proteínas como candidatos para el diagnóstico de la infección humana por MTB. [Tesis]. Universidad de La Habana; 2011.

16. McNamara LA, Yongqun $H$, Zhenhua Y: Use searching a T epitope predictions to evaluate efficacy and population coverage of the MTB72f vaccine for tuberculosis. BMC Immunology 2010, 11:18.

17. Comas Iñaki, Chakravartti Jaidip, Small Peter M, et al: Human T cell epitopes of Mycobacterium tuberculosis are evolutionarily hyperconserved. Nat Genet 2010, 42(6):498-503.

18. Longmate J, York J, La Rosa C: Population coverage by HLA class-I restricted cytotoxic T-lymphocyte epitopes. Immunogenetics 2008, 52(3-4):165-73.

19. Bhasin M, Raghava GPS: A hybrid approach for predicting promiscuous MHC class I restricted T cell epitopes. J. Biosci 2006, 32:31-42.
20. Kumar M, Khan FG, Sharma S, Kumar R, Faujdar J, Sharma R, et al: Identification of Mycobacterium tuberculosis genes preferentially expressed during human infection. Microb Pathog 2011, 50(1):31-8.

21. Mark T, John S, Derek P, Srinivas V, Ramaswamy, Graviss EA, et al: Detection of rpoB Mutations Associated with Rifampin Resistance in Mycobacterium tuberculosis Using Denaturing Gradient Gel Electrophoresis. Antimicrob Agents Chemother 2005, 49(6):2200-09.

22. Banerjee R, Vats P, Sonal D, Sunitha MK, Rajendra J: Comparative Genomics of Cell Envelope Components in Mycobacteria. BMC Microbiol 2009, 14:47.

23. Talaat AM, Lyons R, Howard ST, Johnston SA: The temporal expression profile of Mycobacterium tuberculosis infection in mice. Proc Natl Acad Sci USA 2004, 101(13):4602-7.

24. Abbas AK, Lichtman AH, Pober JS: Inmunología celular y molecular. Barcelona. Elsevier, 62008.

25. Karakousis PC, Yoshimatsu T, Lamichhane G, Woolwine SC, Nuermberger EL, Jacques Grosset, et al: Dormancy Phenotype Displayed by Extracellular Mycobacterium tuberculosis within Artificial Granulomas in Mice. J Exp Med 2004, 200(5):647-657.

doi:10.1186/1471-2172-14-S1-S6

Cite this article as: de la Caridad Addine Ramírez et al:: In silico identification of common epitopes from pathogenic mycobacteria. BMC Immunology 2013 14(Suppl 1):S6.

\section{Submit your next manuscript to BioMed Central and take full advantage of:}

- Convenient online submission

- Thorough peer review

- No space constraints or color figure charges

- Immediate publication on acceptance

- Inclusion in PubMed, CAS, Scopus and Google Scholar

- Research which is freely available for redistribution
C Biomed Central 